\title{
La asistencia a clases de los estudiantes en la educación media superior. Aportes desde una investigación etnográfica en la Ciudad de México Upper-Secondary Students' Attendance. Contributions of an Ethnographic Research in Mexico City
}

\author{
Mercedes Saccone \\ Facultad de Humanidades y Artes, \\ Universidad Nacional de Rosario, Argentina \\ sacconemercedes@gmail.com
}

\section{RESUMEN}

Se analiza la problemática de la asistencia a clases de los estudiantes de nivel medio superior, temática que cobra centralidad en tiempos de obligatoriedad de la Educación Media Superior (en México, desde 2012), dada su influencia en la configuración de procesos particulares de aprobación, reprobación y recuperación. Los resultados que se presentan derivan de una investigación etnográfica sobre la acreditación de asignaturas en la vida cotidiana escolar realizada entre 2014 y 2016 en un plantel del Colegio de Bachilleres de la Ciudad de México. El trabajo de campo consistió en observaciones, conversaciones informales y entrevistas semiestructuradas (grupales e individuales) con estudiantes y otros sujetos que participan de la vida cotidiana escolar. Entre los aportes del enfoque etnográfico se destaca la posibilidad de recuperar relacionalmente la diversidad de voces (estudiantes, docentes, coordinadores) y los procesos de negociación y resignificación de distintos criterios -entre los que se destaca la asistencia a clases- que configuran la acreditación de asignaturas a nivel de la cotidianidad escolar. La acreditación escolar -y los criterios que la configuran- se encuentra atravesada por un mandato presente en las políticas educativas actuales de mejorar los índices en relación con el acceso, la permanencia y la aprobación de los jóvenes en las instituciones del nivel medio superior. Dicho mandato ejerce influencia, pero también es resignificado y tensionado, a nivel de las prácticas y sentidos que construyen los sujetos en la vida cotidiana escolar. Si bien los resultados no pretenden ser generalizables cuantitativamente, pueden ser retomados en la generación de propuestas orientadas a la Educación Media Superior, que recuperen las expectativas, prácticas y sentidos de sus protagonistas.

\section{ABSTRACT}

The objective of this article is to analyze the problem of student class attendance at the upper secondary level. The theme becomes fundamental in times of compulsory Upper Secondary Education (since 2012 in Mexico), given its influence on the setting of specific processes of approval, disapproval, and recovery. The results presented derive from an ethnographic research, carried out between 2014 and 2016, about the accreditation of subjects in daily school life in a campus of Colegio de Bachilleres in Mexico City. The fieldwork consisted of observations, informal conversations and semi-structured interviews (group and individual) with students and other subjects who participate in daily school life. Among the contributions of the ethnographic approach, the possibility of rescue the diversity of voices (students, teachers, coordinators) and the negotiation and redefinition processes of different criteria among which class attendance stands out that shape the accreditation of subjects at the level of daily school life. I argue that the school accreditation -and the criteria that configure it is influenced by current educational policies to improve the indexes considering access, permanence, and approval in institutions of upper secondary level. That administrative mandate causes tensions at the level of the practices and senses that construct the subject in everyday school life. Although the results are not intended to be quantitatively generalizable, they can be retrieved on the generation of proposals aimed at Upper Secondary Education, which recover the expectations, practices, and senses of its protagonists.
Palabras clave: asistencia escolar, Educación Media Superior, jóvenes, etnografía, Ciudad de México.
Keywords: school attendance, Upper Secondary Education, youth, ethnography, Mexico City. 


\section{INTRODUCCIÓN}

El objetivo de este artículo es analizar la problemática de la asistencia a clases de los estudiantes en el nivel medio superior, a partir de recuperar los resultados de una investigación etnográfica realizada entre 2014 y 2016, cuyo objetivo central fue conocer cómo se configura la acreditación de asignaturas en la cotidianidad de un plantel de una institución (Colegio de Bachilleres) ${ }^{1}$ de Educación Media Superior (EMS) en la Ciudad de México. ${ }^{2}$

Esta temática cobra centralidad en tiempos de obligatoriedad de la EMS (desde 2012 en México), dada su influencia en la configuración de procesos particulares de aprobación, reprobación y recuperación. Como profundizamos en otro trabajo (Saccone y Weiss, 2017), la acreditación escolar -y los criterios que la configuran- está atravesada por el mandato de las políticas educativas actuales que buscan mejorar los índices en relación con el acceso, la permanencia y la aprobación de los jóvenes en las instituciones del nivel medio superior. En este contexto, la asistencia a clases se constituye, a nivel de la cotidianidad escolar, en uno de los principales criterios de acreditación de asignaturas, mientras se reduce la exigencia de tareas para realizar en el hogar, se tiende a evaluar sólo a partir de los trabajos realizados en clase, restringiendo la toma de exámenes, y se amplían los mecanismos de recuperación de materias reprobadas (Saccone y Weiss, 2017). Si bien dicho mandato ejerce influencia, también es resignificado y hasta tensionado a nivel de las prácticas y sentidos que construyen los sujetos.

Las investigaciones que analizan la temática en México, fundamentalmente desde perspectivas cuantitativas, atienden en particu-

\footnotetext{
${ }^{1}$ El Colegio de Bachilleres es una institución federal que atiende a 90 mil estudiantes en su opción presencial impartida en 20 planteles ubicados en la Zona Metropolitana de la Ciudad de México. Ofrece un bachillerato general propedéutico que prepara para los estudios de nivel superior. Existen otros dos tipos de servicios de EMS en México: Bachillerato Tecnológico Bivalente (formación técnica y también prepara para la continuación de estudios de tipo superior) y Educación Profesional Técnica (técnicos en actividades industriales y de servicios)

${ }^{2}$ La investigación se realizó en el marco de la tesis de Maestría en Ciencias en la Especialidad en Investigaciones Educativas titulada La acreditación de asignaturas en la vida cotidiana escolar. Un estudio etnográfico en el contexto de la obligatoriedad de la Educación Media Superior, bajo la dirección del Dr. Eduardo Weiss, en el Departamento de Investigaciones Educativas del CINVESTAV. Para su desarrollo se contó con el apoyo de una beca del programa CLACSO-CONACYT.
} 
lar a su vinculación con los procesos de aprobación y de interrupción o "abandono escolar", pero apenas indagan en la problemática de la asistencia a clases ${ }^{3}$ en el nivel de la cotidianidad de las escuelas. A su vez, este aspecto suele ser retomado casi exclusivamente en términos de "inasistencias", como la cara opuesta de la asistencia, en cuanto se trata de un dato que es posible "cuantificar".

De allí que uno de los aportes del enfoque etnográfico es la posibilidad que brinda de realizar un abordaje relacional (Achilli, 2005), que tenga en cuenta los diferentes niveles y dimensiones de análisis en juego (políticos, administrativos, burocráticos, las múltiples mediaciones y apropiaciones de los sujetos involucrados, así como las prácticas y el sentido que construyen y que claramente trascienden las "regulaciones", pero, al mismo tiempo, se imbrican en su concreción) y que permita documentar procesos, sentidos y prácticas. De este modo, la investigación se propone recuperar la diversidad de voces (estudiantes, docentes, coordinadores, otros) y los procesos de negociación y resignificación de distintos aspectos que configuran la acreditación de asignaturas en esta escuela (preocupación central de la investigación) focalizando en la asistencia a clases. Analiza la problemática en relación con los procesos administrativos/burocráticos que la atraviesan, pero también interesa describir los sentidos y prácticas que los estudiantes construyen al respecto, que trascienden tal dimensión. Sentidos y prácticas que construyen, no en forma aislada, sino en el intercambio y en relación con otros sujetos que participan de la vida cotidiana escolar, en un contexto atravesado por la obligatoriedad de la EMS y las políticas que intentan apuntalarla.

Si bien los resultados no pretenden ser generalizables cuantitativamente, pueden resultar un insumo interesante para la generación de propuestas (políticas e institucionales) que busquen apuntalar los recorridos escolares de los jóvenes en la Educación Media Superior, que atiendan a las expectativas, prácticas y sentidos de sus protagonistas.

\footnotetext{
${ }^{3}$ Dado que la "asistencia escolar" suele definirse como el hecho de entrar y permanecer en la escuela durante la jornada escolar, en este trabajo se utiliza el término "asistencia a clases" con la intención explícita de acentuar que la asistencia a la escuela no implica necesariamente el ingreso a las clases.
} 
A continuación, se retoman los principales antecedentes de la investigación y se describen los aspectos metodológicos de la misma. Luego se desarrollan los resultados del estudio y las conclusiones.

\section{ANTECEDENTES Y METODOLOGÍA DE LA INVESTIGACIÓN}

La temática de la evaluación ha sido abordada ampliamente y desde diversas perspectivas en México, destacándose en la actualidad las investigaciones sobre la evaluación de políticas educativas (Amador, 2008; Kisilevsky, 2009); la evaluación de la "calidad" de los sistemas educativos (Martínez Rizo, 2009; Martinic, 2010, y Poggi, 2008); la evaluación docente (Rockwell, 2013; Schmelkes, 2013); y las "pruebas estandarizadas de rendimiento" (Campos y Urbina, 2011; Treviño, 2006). Granja (1988) estudió a nivel normativo la "certificación escolar" en la enseñanza tecnológica agropecuaria del nivel medio superior, diferenciándola de la evaluación, en tanto proceso más amplio de legitimación de los aprendizajes que culmina con la titulación. Su conceptualización de "certificación escolar" como "proceso permanente de examinaciones y registros de los aprendizajes logrados por cada alumno" (Granja, 1988, p. 24), sirve para pensar la acreditación de asignaturas como parte de la certificación. A su vez, las acreditaciones constituyen una de las interfaces visibles entre la institución escolar y la sociedad, una especie de certificación de conocimientos y habilidades adquiridas y una legitimación del portador para participar en determinados ámbitos escolares, profesionales y sociales. Otros investigadores también han indagado en el carácter legitimador y selectivo de la escolarización y los efectos sociales de las evaluaciones y certificaciones escolares (Bourdieu y Passeron, 1998; Dore, 1980; Jackson, 1998). Pero aún queda mucho por conocer acerca de la acreditación de asignaturas y los criterios que la conforman en el nivel medio superior en el contexto mexicano, en especial sobre los modos concretos que van adquiriendo y cómo son apropiados y significados por los sujetos en la vida cotidiana de las escuelas.

En cuanto a la temática de la "asistencia a clases", ésta suele aparecer en las investigaciones vinculadas a la problemática del 
"abandono" o interrupción escolar ${ }^{4}$ (Blanco, Solís y Robles, 2014; SEMS, 2012; Estrada, 2015; Guerra, 2008; Miranda, 2012; Muñoz, Rodríguez, Restrepo y Borrani, 1979; Solís, Leal y Brunet, 2014; Weiss, 2014; entre otros). Aunque desde diferentes perspectivas, estos estudios coinciden en señalar que son múltiples los factores que intervienen en la interrupción de los estudios y pueden incluir entre ellos las "inasistencias" reiteradas, resaltando, en algunos casos, su vinculación con causas económicas (como la necesidad de trabajar para aportar a la economía del hogar relegando los estudios formales). Además, advierten la necesidad de considerar los "eventos previos de la trayectoria de los estudiantes que pueden incidir en su propensión a salir de la escuela", por lo tanto "la interrupción escolar puede verse, en ese sentido, como el resultado de un proceso de progresiva desafiliación de la institución escolar, caracterizado por el incremento en las inasistencias, bajo rendimiento, o una débil integración social"s (Blanco, 2014, p. 47). De allí que resulte relevante profundizar en el conocimiento de lo que sucede a nivel de la cotidianidad escolar con la asistencia a clases, atendiendo en particular a los sentidos y prácticas que los sujetos construyen al respecto. A su vez, ello permitirá aportar al análisis de la complejidad del tema, estableciendo relaciones con otros procesos más allá de la interrupción o "abandono" escolar.

Con la intención de aportar al conocimiento en este campo temático, realicé el estudio en el que se basa este trabajo entre septiembre de 2014 y julio de 2016, desde una perspectiva etnográfica que retoma las tradiciones del Departamento de Investigaciones Educativas del Centro de Investigaciones y de Estudios Avanzados (DIECINVESTAV, México) y del Centro de Estudios Antropológicos en Contextos Urbanos de la Facultad de Humanidades y Artes de la Universidad Nacional de Rosario (CeaCu, FHyA, UNR, Argentina). Desde este enfoque y a partir de la recuperación de la línea de in-

\footnotetext{
${ }^{4}$ El término "interrupción" se hace referencia "de manera genérica, a cualquier evento que suponga un corte en la continuidad de la trayectoria escolar" (sea "inter-grado", "intragrado", "inter-nivel", "intra-nivel. Véase Blanco, 2014).

${ }^{5}$ El estudio referido se realizó a partir de la Encuesta sobre Trayectorias Educativas y Laborales de los Jóvenes de la Zona Metropolitana de la Ciudad de México 2010 que, de acuerdo con los investigadores, posee limitaciones para realizar un relevamiento sistemático de las experiencias vinculadas con ese proceso de desafiliación progresiva (Blanco, 2014).
} 
vestigación sobre Jóvenes y escuela dirigida por Eduardo Weiss y los desarrollos de Rockwell (2009) y Ezpeleta (2004) sobre el proceso escolar, intento "comprender algunos procesos sociales y prácticas culturales, especialmente a escala cotidiana” (Rockwell, 2009, p. 184). Allí la normativa oficial, en este caso, la referente a la acreditación de asignaturas y, puntualmente, al criterio de la asistencia, adquiere un lugar relevante, pero es sólo a través de la "reinterpretación [que] los actores escolares se apropian -es decir, filtran, reconstruyen y hacen propias-" (Weiss, 2016, p. 18) de la misma. La apropiación, como propone Rockwell (2005), conlleva, de manera simultánea, el sentido de la naturaleza activa de la acción humana y el carácter constrictivo y permisivo de la cultura. De allí que el análisis realizado pretendió atender al mismo tiempo los procesos administrativos, normativos, burocráticos, pero también las apropiaciones y resignificaciones que los sujetos, en especial los estudiantes, realizan en el entrecruzamiento de relaciones, procesos y prácticas cotidianas que claramente trascienden el nivel normativo, pero a través de las cuales adquieren concreción.

La investigación se desarrolló en un plantel del Colegio de Bachilleres de la zona sur de la Ciudad de México. ${ }^{6}$ Formalmente, ningún tipo de institución de EMS impide continuar con estudios de nivel superior, pero "las distintas modalidades no abren las mismas puertas" (Villa, 2007, p. 109), ya que "no respaldan de la misma manera la calidad del aprendizaje” (De Ibarrola, 2012, p. 18). De hecho, el Colegio de Bachilleres y el Colegio Nacional de Educación Profesional Técnica (Conalep) “concentran también -junto con el telebachillerato y las modalidades a distancia- los más bajos resultados en las pruebas de aprovechamiento escolar" (Ramírez y Torres, 2015, p. 223). Además, en comparación con otras instituciones de EMS, como las pertenecientes a la Universidad Nacional Autónoma de México: "los jóvenes que ingresan al ColBach poseen en promedio niveles socioeconómicos más bajos... y, al mismo tiempo, suelen no haber tenido a esta institución como su opción preferida para ingresar al bachillerato" en el examen de asignación a cargo de

\footnotetext{
${ }^{6} \mathrm{El}$ nombre del plantel y de los sujetos no se mencionan o fueron reemplazados por seudónimos para mantener el anonimato.
} 
Comipems $^{7}$ (Solís et al., 2014). Las diferencias entre los planteles que posee el Colegio de Bachilleres en la Zona Metropolitana de la Ciudad de México también son significativas. Por ejemplo, la cantidad de aciertos mínimos requeridos en el examen de Comipems para el ingreso 2015 más alta fue de 85 aciertos, mientras que la más baja presentó 19 aciertos $^{8}$ (Comipems, 2016).

En cuanto al porcentaje de deserción anual para el ciclo escolar 2013-2014, también se pueden observar diferencias significativas entre los 20 planteles del Colegio de Bachilleres, que van desde $14.6 \%$ en el plantel de mayor prestigio, hasta $30.4 \%$ de deserción anual en uno de los menos requeridos (Plantel Colegio de Bachilleres, 2014a). El plantel donde realicé el trabajo de campo se ubica entre aquellos que poseen mayor índice de reprobación, reportando 27.9\% para el ciclo 2013-2014 (Plantel, Colegio de Bachilleres, 2014 a, p. 2) y cuenta con una matrícula aproximada de 2500 estudiantes (58\% asiste al turno matutino y $42 \%$ al vespertino) (Plantel, Colegio de Bachilleres, 2015), "aunque su capacidad instalada es para la atención de hasta 2000 alumnos" (Plantel, Colegio de Bachilleres, 2012). En el periodo 2013-2014 63\% de los estudiantes del plantel recibía una beca o algún tipo de ayuda económica (Plantel, Colegio de Bachilleres, 2014a)

Para la construcción de información empírica recurrí a diferentes estrategias: observaciones, conversaciones informales y entrevistas semiestructuradas (grupales e individuales) con estudiantes, docentes, coordinadores, orientadores, tutores, jefes de materia, padre. También revisé fuentes documentales institucionales, normativas, leyes, entre otras.

Desde el enfoque seleccionado, el resultado del proceso de investigación, lo que Rockwell (2009, p. 75) denomina "objeto de

\footnotetext{
${ }^{7}$ En la Zona Metropolitana de la Ciudad de México, la asignación de los egresados de secundaria a los planteles de EMS se realiza mediante el examen de la Comisión Metropolitana de Instituciones Públicas de Educación Media Superior (Comipems). Dado que hay instituciones más demandadas porque ofrecen mayor probabilidad de ingresar posteriormente a las universidades públicas más prestigiosas, el examen de Comipems se convierte en "una instancia fuertemente selectiva en lo social" y "en términos académicos" (Blanco et al., 2014).

${ }^{8}$ Cabe mencionar, a modo de comparación, que las instituciones de EMS dependientes de la UNAM y el IPN más prestigiosas poseen, como línea de corte, números mayores a los 80 puntos, incluso muchas de ellas sobrepasan los 100 aciertos como mínimo requerido (Comipems, 2016).
} 
estudio", "toma finalmente la forma de un texto, una serie de narraciones y descripciones organizadas de tal manera que muestren ciertas relaciones de un entramado real que siempre será más complejo”.

En esta oportunidad, me interesa profundizar en uno de los criterios de acreditación de asignaturas regulares en este plantel del Colegio de Bachilleres: la asistencia a clases. Para ello, describiré algunas prácticas, sentidos y procesos vinculados al criterio de la asistencia a escala de sus configuraciones cotidianas, entendiendo que se encuentran impregnados de contenido histórico social (Achilli, 2010) y, por lo tanto, se construyen en el cruce entre los procesos estructurales y la historia particular de cada escuela (Rockwell y Ezpeleta, 1985).

\section{Criterios de acreditación escolar en el contexto de la obligatoriedad de la EMS}

Entre las políticas que tienen como foco la EMS en la última década se destaca la modificación del artículo $3^{\circ}$ de la Constitución Política, para establecer la obligatoriedad de este nivel educativo a partir de 2012. La obligatoriedad aparece ligada al compromiso del Estado de "ofrecer un lugar para cursarla" y así poder "lograr la cobertura total" que se prevé realizar "de manera gradual", "hasta lograr la cobertura total” en 2021-2022 (Diario Oficial de la Federación, 2012). Explícitamente se establece:

La obligatoriedad del Estado de garantizar la educación media superior, como deber del mismo de ofrecer un lugar para cursarla a quien teniendo la edad típica hubiera concluido la educación básica, se realizará de manera gradual y creciente a partir del ciclo escolar 2012-2013 y hasta lograr la cobertura total en sus diversas modalidades en el país a más tardar en el ciclo escolar 2021-2022 (Diario Oficial de la Federación, 2012).

"Obligatoria o no, la educación media es tema de preocupación en muchos países y está presente en las agendas de organismos internacionales" (Instituto Nacional para la Evaluación de la Educación, INEE, 2011, p. 24). A nivel regional, existe cierto consenso 
respecto a que se estaría produciendo un cambio de definición en relación con la educación media, comenzando a concebirla como "parte constitutiva de la educación fundamental que todo ciudadano debiera poseer, y ya no como una situación excepcional o de privilegio" (Bellei, 2012, p. 220).

En este escenario, las políticas educativas locales establecieron metas ambiciosas. Se destaca la pretensión de aumentar la tasa de escolarización de jóvenes de entre 15 y 17 años en la EMS hasta alcanzar la cobertura total. A su vez, la Subsecretaría de Educación Media Superior (SEMS) pretendía disminuir la tasa de abandono escolar de $15 \%$ en 2012, a 9\% para 2018 (Consejo Nacional de Autoridades Educativas, Conaedu, 2015), más de un tercio. Aunque no se lograron las metas propuestas, según datos del Conaedu (2015, s.p.) "la matrícula escolarizada se elevó en casi setecientos mil estudiantes entre 2012-2013 y entre 2016-2017, y la no escolarizada, en 360000 estudiantes. De esta manera, se logró una cobertura escolarizada de $76.6 \%$ " para dicho periodo (Weiss, 2018, p. 2). A su vez, el promedio nacional de deserción escolar en media superior mejoró lentamente de $16.5 \%$ en 2005-2006 a 15\% en 2011-2012 (Weiss, 2014 y 2015) y a 13.4\% en 2013-2014 (Conaedu, 2015). Vale aclarar que ciertas instituciones, como el Colegio de Bachilleres, presentan tasas de abandono escolar considerablemente mayores al promedio (Solís, Leal y Brunet, 2014).

Para lograr una mayor cobertura en la EMS también adquirió fuerza en los últimos años el mandato de disminuir los índices de abandono. Entre las acciones llevadas adelante se destaca la ampliación de los programas de becas y el "Movimiento contra el abandono escolar", ', además, explícitamente, se planteó la necesidad de revisar y flexibilizar los reglamentos escolares y los mecanismos de evaluación para que no limiten la posibilidad de regularización y permanencia de los estudiantes (Conaedu, 2015). En ese sentido,

\footnotetext{
${ }^{9}$ El Movimiento contra el abandono escolar (antes, Síguele) parte de considerar que las medidas más pertinentes en pos de disminuir el abandono se deben tomar en los planteles y prevé la elaboración por parte de los equipos directivos, docentes y padres de cada plantel de un Plan contra el abandono escolar, con acciones concretas (Weiss, 2015a). Como parte de esta política se capacitó a directivos y docentes; "se elaboró y actualizó una Caja de Herramientas (con 6 manuales en 2013 y 12 manuales en 2014), y se asignaron más de 216 mil becas contra el abandono escolar en el ciclo 2013-2014" (Conaedu, 2015, p. 29).
} 
"una de las medidas centrales fue comprometer a los directores de escuelas a elaborar un plan contra el abandono escolar en el que se responsabilizaran con determinadas metas a alcanzar" (Weiss, 2018, p. 4). "En este contexto, las escuelas han comenzado a modificar sus reglamentos de regularización" y "muchas escuelas han dejado de reportar todas las ausencias de los alumnos al 'sistema' para circunvenir la reprobación automática” (Weiss, 2018, p. 10).

\section{Obligatoriedad de la EMS y asistencia a clases en el Colegio de Bachilleres}

... la condición estadística de aprobación, reprobación o permanencia, ¿qué es la permanencia? Es la asistencia a clases de los alumnos, ¿por qué? Porque es lo que tenemos que demostrar, que estamos al pendiente de ellos; es lo que tenemos que demostrar

Tutor-Prof. Ética, Comunicación personal, 08/05/15

Las instituciones escolares poseen un carácter "legitimador" que se materializa en el proceso de certificaciones escolares y en la emisión de los títulos académicos (Granja, 1988). Como parte de la certificación escolar, los jóvenes deben sortear la acreditación de asignaturas, proceso a través del cual se certifican y legitiman los aprendizajes de los estudiantes en el trayecto correspondiente a una determinada asignatura. ${ }^{10}$

Con la intención de describir la acreditación escolar en el plantel del Colegio de Bachilleres donde realicé el trabajo de campo, identifiqué dos grandes ejes:

1. La acreditación de asignaturas regulares, a través de criterios que incluyen: la asistencia a clases (cuya descripción presento en este artículo), exámenes, participación en clase, la realización y entrega de trabajos y tareas;

\footnotetext{
${ }^{10}$ Cabe aclarar que no sólo se consideran los aprendizajes logrados y expresados a través de exámenes, trabajos, tareas, sino que también se valoran las "disposiciones actitudinales", ello "conlleva un conjunto de juicios calificadores informales emitidos tanto por los maestros como por los propios alumnos a través de los cuales se estructura una caracterización de cada estudiante a lo largo de su permanencia en la institución" (Granja, 1988, p. 2).
} 
2. Los mecanismos de recuperación que constituyen una instancia de acreditación escolar que se produce cuando los jóvenes reprueban una asignatura determinada: exámenes extraordinarios, Programa de Acreditación Intensivo, Grupos de estudio.

Estos criterios, que configuran la acreditación escolar, se encuentran atravesados por el mandato presente en las políticas educativas actuales de mejorar los índices en relación con el acceso, la permanencia y la aprobación de los jóvenes en las instituciones del nivel medio superior (Saccone y Weiss, 2017). Dicho mandato ejerce influencia, pero también es resignificado y hasta tensionado a nivel de las prácticas y sentidos que construyen los sujetos en la cotidianidad escolar.

Como mencioné, entre los criterios formales de acreditación regular de cursos del Colegio de Bachilleres se encuentra la asistencia a clases. Aunque es sabido que existe siempre una distancia "entre las exigencias institucionales -expresadas en las normatividades- y las prácticas y elaboraciones sociales de los actores que significan o resignifican de diferente modo dichas exigencias" (Estrada, 2014, p. 436), pude observar que la asistencia constituye una preocupación central en la vida cotidiana de esta escuela. En palabras del Jefe de la Academia de Filosofía: "lo que más nos interesa es esta situación ... que el alumno, pues, pueda... seguir concurriendo ¿no?, que su asistencia se haga efectiva ... disminuir el ausentismo" (Jefe Filosofía, Comunicación personal, 04/06/15). Como se puede advertir en el fragmento de entrevista que retomo a modo de epígrafe de este apartado, las acciones que docentes y coordinadores realizan en pos de mejorar la continuidad de la asistencia a clases es algo que tienen que "demostrar" (Tutor-Prof. Ética, Comunicación personal, 08/05/15). Incluso los estudiantes reconocen que la asistencia "es lo que más importa, porque hay mucha deserción de la escuela” (Karen estudiante de 2do semestre, Comunicación personal, 10/03/15). En consonancia con esas preocupaciones, el equipo directivo a cargo del plantel decidió (en 2012) que, una vez que los jóvenes ingresan al establecimiento, no tienen permitido salir hasta que hayan concluido la jornada escolar, salvo algunas excepciones (como la ausencia del profesor que dicta la última materia, enfermedad, permiso para 
retirarse por motivos personales). Pero el ingreso al salón no está igualmente controlado y es el propio joven quien decide si asiste o no a cada clase. Aquellos que entran al plantel, pero no asisten a clases suelen quedarse en los espacios comunes que posee la escuela (biblioteca, patios, cafetería).

Según el artículo 85 del Reglamento general de los alumnos, el mínimo porcentaje de asistencia requerido para acreditar un curso es de $80 \%$ (Colegio de Bachilleres, 2010). Este criterio puede ser flexible y su ponderación porcentual respecto a la calificación final puede variar de un docente a otro, de materia a materia o de una academia a otra.

A diferencia de los planteos respecto a la centralidad de hacer "efectiva" la asistencia a clases que mencioné, hay otros docentes que no le otorgan tanta relevancia al control de la asistencia de los estudiantes, planteando que "la asistencia no garantiza, o el que permanece el alumno no garantiza que aprende o que va a salir, no me garantiza nada de eso" (Profesora de Biblioteconomía, Comunicación personal, 15/03/16). Sin embargo, la impresión de los jóvenes es que para la mayoría de sus docentes la asistencia es lo más importante, al punto de aprobar con "pura asistencia" en algunos casos:

$\begin{array}{ll}\text { Yayis: } & \text { evaluaba más con la asistencia que con otra cosa. } \\ \text { Paola: } & \text { sí, era como... tu seis, lo sacabas de pura asistencia. } \\ \text { Entrevistadora: } & {[E]: \text { ¿si querías más nota...? }} \\ \text { Paola: } & \text { ajá, ya eran los trabajos, tareas (Yayis, Dulce y Paola } \\ & \text { estudiantes 2do semestre, Comunicación personal, } \\ & 06 / 05 / 15) .\end{array}$

En palabras de otra estudiante, "hay materias en que sí tienes que entrar a fuerza” (Celeste estudiante 2 do semestre, Comunicación personal, 13/05/15). Según los jóvenes, estos profesores consideran el criterio de la asistencia como requisito fundamental para poder continuar cursando la asignatura, porque "si tienes ya tres faltas [en el semestre], ya te dicen 'ya no entras" (Dulce, estudiante 2 do semestre, Comunicación personal, 06/05/15), o como condición para tener derecho a rendir el examen parcial. Esos docentes argumentan que "como el trabajo se hace aquí, entonces la asisten- 
cia tiene muchísimo peso" (Profesora de Lenguaje, Comunicación personal, 15/03/16) y "es importante [porque], si viniendo, aunque están en calidad de bulto, no aprenden, menos si no entran. Entonces ya entrando ellos tienen oportunidad de participar" (Profesora de Química, Comunicación personal, 15/03/16).

Respecto a la puntualidad en el ingreso a clases, tanto docentes como estudiantes con frecuencia llegan después del horario establecido. Ello se debe, en parte, a que no existe formalmente un espacio temporal que considere el traslado de un salón a otro o tomar un descanso entre una clase y otra. Tampoco hay recesos oficiales. Por lo general, los docentes finalizan su clase cinco o diez minutos antes o comienzan minutos después del horario establecido.

Los profesores pueden otorgar algunos minutos de tolerancia -habitualmente entre 10 y 15- para la llegada de los estudiantes. Aunque en las clases observadas hubo jóvenes que ingresaron hasta 30 o 40 minutos después del inicio. Y en una entrevista grupal comentaban:

Dulce: depende de los maestros, algunos te dan diez minutos, otros quince.

Paola: hasta veinte minutos.

E: $\quad$ ¿hasta veinte te dan?

Dulce: pero si llegas después, te dicen "ya no, adiós".

Paola: hay unos que sí te dan oportunidad, te dan toda la clase. Puedes entrar cinco minutos antes de que acabe su clase

Dulce: $\quad y$ te deja entrar, pero son muy pocos (Dulce y Paola estudiantes 2 do semestre, Comunicación personal, 06/05/15).

Hay profesores que establecen algunos mecanismos de sanción al respecto: "ya no te aceptan la tarea" (Consuelo estudiante 2do semestre, Comunicación personal, 12/02/15) o no te permiten ingresar directamente a la clase, e incluso los jóvenes plantean que, si llegas tarde, puede ocurrir que te "regañan" y "luego te andan exhibiendo" (Roxana estudiante 4to semestre, Comunicación personal, 04/06/15). Teniendo en cuenta estas situaciones, los estudiantes 
pueden decidir no entrar a clase si llegan tarde: "uno solito se hace la idea, no me va a dejar pasar, mejor ya no entro... como para evitarse el regaño" (Brenda estudiante 4to semestre, Comunicación personal, 11/06/15).

Si bien existen diferencias entre los docentes respecto a los criterios de puntualidad y asistencia vinculadas a los estilos y tradiciones diversos existentes entre los mismos, la rigidez y exigencia de ciertos profesores era cuestionada por algunos coordinadores y orientadores, al considerarlo un posible factor de "exclusión”. Apropiándose del mandato de flexibilizar el control de la asistencia a clases, criticaban el accionar de los docentes más "estrictos", manifestando que "hay criterios y hay también flexibilidad en ese sentido ¿no? porque sí, hay una tendencia muy estricta, a veces a ya no dejar entrar al salón al alumno" (Jefe Filosofía, Comunicación personal, 26/05/15). En sentido similar, el Coordinador de Modalidades del plantel afirmaba: "los maestros somos muy exigentes... exigimos mucho, pedimos mucho ... no los dejamos entrar a clases, por ejemplo" (Coord. de Modalidades, Comunicación personal, 09/03/15); un Orientador escolar comentaba al respecto: "no veo bien que el maestro le diga al joven 'yo ya no te quiero en mi clase', a veces uno lo entiende, otras lo excluyen del todo" (Orientador de Turno Mañana, Comunicación personal. 10/03/15).

\section{Entre la "flojera" y el "echarle ganas". Motivos para no asistir a clase}

Los sujetos ofrecen "explicaciones significativas en términos de motivos, que vinculan sus decisiones con ciertas preferencias, expectativas y restricciones" (Blanco et al., 2014, p. 43), así, entre los motivos que señalan los jóvenes por los cuales llegan tarde o faltan a clases se encuentran: el vivir lejos del plantel (Brenda estudiante 4to semestre, Comunicación personal, 11/06/15); "que ya es final [del semestre], como ya ha dado calificaciones antes entonces ya casi nadie entra" (Yayis estudiante 2do semestre, Comunicación personal, 06/05/15); porque tienen otras actividades que se superponen con alguna clase (un campeonato de fútbol, por ejemplo). Se destacan en especial los motivos vinculados a los estilos y exigencias de los do- 
centes. Los jóvenes a veces deciden no entrar a clases para evitar ser regañados -como señalé- o porque no acuerdan con el estilo y personalidad del docente: "es muy enojona la maestra" (Roxana estudiante 4to semestre, Comunicación personal, 04/06/15), "muy estricta” o "mal maestro" (Estudiantes 2do semestre, Comunicación personal, 26/02/15). También aluden a que las clases, con algunos profesores, "son algo aburridas" (Sandra estudiante 2do semestre, Comunicación personal, 24/06/15) y la "forma de trabajo" puede ser "desalentadora", si "nada más es como de 'lean eso y hagan esto"” (Brenda estudiante 4to semestre, Comunicación personal, 11/06/15).

Hay jóvenes que, al no cumplir con los requisitos del docente, deciden no ingresar al salón, "porque no tenía la tarea" (Raúl estudiante 2do semestre, Comunicación personal, 12/02/15). Paola comentaba al respecto: "a mí se me hacía fácil no entrar de repente, ¿no? Yo decía 'ay no sé este tema, no entro”' (Paola estudiante 2do semestre, Comunicación personal, 06/05/15). A veces sucede lo contrario, que los jóvenes deciden entrar a clases justo para cumplir con las exigencias de los profesores. Esto suele ocurrir cuando tienen que entregar algún trabajo (Consuelo estudiante 2 do semestre, Comunicación personal, 12/02/15) o como cuando no están asistiendo y deciden "echarle ganas" porque "ya venían los exámenes” (Karen estudiante 2do semestre, Comunicación personal, 12/03/15). Para negociar con sus docentes, los estudiantes recurren a la estrategia de intentar convencerlos de que en realidad quieren "echarle ganas" y así obtener una nueva oportunidad (para aprobar la asignatura, mejorar calificaciones, realizar un trabajo a destiempo). "Echarle ganas" implica, según los estudiantes, "entregar algunas cosas" (Roxana estudiante 4to semestre, Comunicación personal, 04/06/15), "entrar a las clases, hacer las tareas, participar en clase" (Daniela estudiante 2do semestre, Comunicación personal, 13/05/15) "entrar a mis clases y hacer los trabajos" (Abraham estudiante 2do semestre, Comunicación personal, 18/05/15).

Hay jóvenes que tienen en cuenta las consecuencias negativas que puede acarrear el no asistir a clases: "[En el patio] pasan cuatro jóvenes caminando y uno le dice al otro '¡no manches güey!, si me salgo me sacan un punto”' (Observación, 18/05/15). 
Otro motivo para no asistir a clase destacado en las entrevistas por los estudiantes es la "flojera", significada como no tener ganas. Esto se asocia a veces al día viernes, al horario vespertino, a las últimas semanas del semestre o al estado de ánimo. Este motivo se puede relacionar también con problemas personales de los jóvenes: "no entraba a mis clases por unos problemas que tenía, no tenía ganas de entrar a mis clases así que no, no entraba” (Abraham estudiante 2do semestre, Comunicación personal, 18/05/15).

Entre los docentes la inasistencia a clases de los estudiantes recurrentemente es interpretada como producto del "desinterés", "faltan mucho, no entran a la clase, no les importa, se van de fiesta, es un problema que hay que atender" (Profesor de Ética, Comunicación personal, 26/02/15). Los jóvenes reconocen que a veces se dejan ganar por el "desmadre" (Edgar estudiante 2do semestre, Comunicación personal, 12/03/15) y analizándolo en retrospectiva puede surgir el arrepentimiento, como Javier, que reprobó "11 materias, era muy chavo... te vas a tomar, a cotorrear, me valió madre” (Javier estudiante 2do semestre, Comunicación personal, 26/02/15).

Otro factor interesante es la influencia de los pares en la decisión de entrar o no a clases. Es frecuente observar en el patio del plantel situaciones como la siguiente:

Llegan dos chicos y se acercan a dos jóvenes que están sentadas en el cantero.
Ariel: ¿¿no tienen clase?
Juana: $\quad$ sí, Química.
Ariel: nosotros también teníamos Química, pero nos meti- mos para salirnos (risas) entonces están aquí ¿̨haciendo? Juana y María: nada (Observación, 18/05/15).

En ocasiones los jóvenes deciden no ingresar a clases para "pasar el rato" con sus pares "o los amigos que te dicen que vamos a una fiesta o vamos a dar la vuelta o algo así" (Roxana estudiante 4to semestre, Comunicación personal, 04/06/15), o con sus novios: "yo tengo novia en el plantel, pero por la diferencia de horarios no nos vemos. A veces me salto y después recupero" (Edgar estudiante 2do semestre, Comunicación personal, 12/02/15). 
Como proponen los estudios de la línea de investigación sobre Jóvenes y escuela del Departamento de Investigaciones Educativas (CINVESTAV-IPN), la escuela también es vivida y significada por los estudiantes como "espacio de vida juvenil" (Weiss, 2012, 2015). La sociabilidad, en el sentido que le asigna Simmel (2002) es importante para los jóvenes que disfrutan estar juntos (Ávalos, 2009; Hernández, 2008; Grijalva, 2011; Weiss, 2012, 2015). Puede ocurrir que las posibilidades de la vida juvenil compitan con algunos de los requerimientos escolares (Weiss, 2012, 2015), como cuando el grupo de amigos invita a faltar a clases (Guerrero, 2008; Hernández, 2008).

Las escuelas son espacios privilegiados para ser jóvenes y establecer contacto con pares, pero éstas no siempre lo favorecen (Weiss, 2012, 2015). Un procedimiento que se despliega en este plantel, ante el cual los estudiantes muchas veces plantean rechazo, consiste en la redistribución de los grupos al iniciar el segundo semestre. Esta redistribución se realiza, según explicaciones del Coordinador de Modalidades, porque "va disminuyendo la cantidad de alumnos ... entonces, lo que hacemos es volver a armar grupos de 40 otra vez y pues ya empezamos a jalar de otros salones" sin un criterio preestablecido (Coord. de Modalidades, Comunicación personal, 09/03/15). Sin embargo, los jóvenes seńalaban que los cambian porque "no quieren que los grupos que se hicieron sigan, porque a veces los grupos son demasiado desastrosos ${ }^{11}$... entonces, prefieren revolver todo" (Dulce estudiante 2do semestre, Comunicación personal, 06/05/15). También pueden ver el lado positivo, como Celeste que lo consideraba "mal porque te separan, bueno, aunque también conocemos a otros" (Celeste estudiante 2do semestre, Comunicación personal, 13/05/15). Pero algunos estudiantes afirmaban que "nos remueven del grupo por eso nos saltamos de clase” (Raúl estudiante 2do semestre, Comunicación personal, 12/02/15), mostrando la posible influencia de ese procedimiento escolar en la decisión de optar por faltar a clase para reunirse con los antiguos compañeros.

No obstante, en la investigación realizada observé que las amistades no sólo influyen en la decisión de no asistir a clase, como suelen documentarlo otras investigaciones, sino que también pueden incidir en forma contraria:

\footnotetext{
${ }^{11}$ Desordenados, revoltosos, que no cumplen con ciertas normas de convivencia escolar.
} 
Yayis: $\quad$ a veces las amistades influyen mucho ... por ejemplo, ella [Dulce] me dice "no, hay que entrar y ve" y "haz esto" y "ve" y "no, no".

E: ¿ella es la que te dice que entres? (risas).

Yayis: me lleva literalmente de la mano al salón "vamos" y yo digo "sí, vamos", y voy (riéndose) (Yayis estudiante 2do semestre, Comunicación personal, 06/05/15).

Como afirmaba Weiss (2015, p. 10), "las experiencias de los jóvenes no se limitan al hedonismo ni a la sociabilidad", dado que "los estudiantes tienen obligaciones escolares y aún la convivencia juvenil y los encuentros con compañeros, amigos y parejas significan más que sólo vibrar juntos". Los estudiantes se encuentran atravesados por la necesidad de responder a las demandas escolares y, al mismo tiempo, son atraídos por la vida juvenil (Grijalva, 2011). Así, la condición de ser joven y de ser estudiante no necesariamente siempre se oponen (Weiss, 2012).

La importancia de los grupos de pares en las experiencias escolares de los jóvenes es destacada por diversos autores (Dubet y Martuccelli, 1998; Guerrero, 2008; Grijalva, 2011; Hernández, 2008; Kantor, 2015; Ramírez, 2012; Weiss, 2012, 2015). Como vimos, a la hora de decidir si se ingresa o no a clases, la influencia de los amigos, compañeros, novios, es fundamental. Los jóvenes reconocen la influencia de los pares y afirman que "pues ya decides tú con quién te juntas y con quién no, ¿no?” (Roxana estudiante 4to semestre, Comunicación personal, 04/06/15).

\section{ASISTENCIA/INASISTENCIA Y EL SENTIDO MORAL DE LA “LIBERTAD CON RESPONSABILIDAD”}

En las entrevistas con los jóvenes, la decisión de entrar o no a clases aparecía atravesada por el sentido, asociado al bachillerato, del ejercicio de la libertad con responsabilidad (Guerrero, 2008). "Tanto las familias como los establecimientos escolares suelen otorgar a los estudiantes del nivel medio superior mayor libertad para decidir sobre el uso de su tiempo" (Weiss, 2015, p. 20). Similar a lo que expresan Dubet y Martuccelli (1998) en relación con los jóvenes liceístas 
franceses que se encuentran sometidos a un imperativo de "libertad" y el control social más directo se debilita llegando a reducirse a la exigencia única de las calificaciones.

Sabemos que en las escuelas se transmiten concepciones del mundo, "una serie de interpretaciones de la realidad y de ordenaciones valorativas" (Rockwell, 1995, p. 45) y que históricamente se ha expresado una "preocupación porque los educandos adquieran principios morales que les ayuden a conformar sus conductas de acuerdo con determinados modelos de moralidad que se consideran deseables" (Latapí, 1999, p. 19). Este sentido de la "libertad con responsabilidad" se relaciona con un modelo de moralidad que plantea que los seres humanos tienen la "capacidad de elegir, de modo libre y responsable, entre opiniones diferentes” (Latapí, 1999, p. 27).

Los jóvenes entrevistados señalaban que, a diferencia de la secundaria, en el bachillerato cuentan con mayor margen de "libertad" para decidir si entrar o no a clases. Algo similar documentan investigaciones desarrolladas en otras instituciones de educación media superior en México (en el Colegio de Ciencias y Humanidades Guerrero, 2008, y Hernández, 2008; en Conalep, Saucedo, 1998) y en Francia (Dubet y Martuccelli, 1998). Así lo explicaba una estudiante de 4to semestre de este plantel del Colegio de Bachilleres:

Más libre, ¿no?, yo creo porque en la secundaria, pues, obviamente, era de escuela cerrada, ¿¿no?, y aquí, en el Bachilleres, si quieres entras y si quieres no. No le hablan a tus papás para andarle diciendo "no llegó su hija” o “¿por qué no ha venido su hija?”. En la secundaria le marcan a tus papás si no vienen a la firma de tus calificaciones, ¿̨no?, aquí ya decides tú si entras o no entras... no te dicen nada (Roxana estudiante 4to semestre, Comunicación personal, 04/06/15).

Los estudiantes entrevistados consideran que en secundaria había un mayor control por parte de los adultos para que ingresaran a sus clases, "te saltabas de clase y ya venía el prefecto 'métete a tu clase' y aquí puedes estar aquí [en el patio] y pasan los maestros, el director" (Dulce estudiante 2do semestre, Comunicación personal, 
06/05/15); "no te dicen nada" (Yayis estudiante 2do semestre, Comunicación personal, 06/05/15). La "libertad" es significada como la posibilidad de decidir por sí mismos, en este caso decidir si entrar o no a clases, y no ser sancionados por ello. Algunos jóvenes valoran positivamente esta "libertad" y la mayor independencia con que cuentan en el bachillerato:

ahora es como que es tu vida, tú sabes lo que haces, si entras o no, si entregas trabajo... nadie te obliga a nada. Ellos ponen los maestros, la educación y el plantel y tú pones lo demás ... te va formando para un futuro, no todo el tiempo van a estar tras de ti, entonces está bien que te vuelvas más... independiente (Abraham estudiante 2do semestre, Comunicación personal, 18/05/15).

Esta mayor "libertad" que brinda el bachillerato es asociada por los estudiantes a la responsabilidad y maduración y formación de sí mismos. Afirman que "es responsabilidad de cada uno, si tú quieres ir a embriagarte o estar afuera todo el día sentado, o no entrar a tus clases, eso ya es algo que cada quien debe de pensarlo" (Abraham estudiante 2do semestre, Comunicación personal, 18/05/15).

Pero esta "libertad" varía de acuerdo con las tradiciones y características de la institución de que se trate. En el Colegio de Ciencias y Humanidades dependiente de la UNAM, por ejemplo, además de la posibilidad de dejar de asistir a clases y de vestir de manera particular como ocurre en el Colegio de Bachilleres, los jóvenes entran y salen del plantel en cualquier momento y hasta fuman o prueban alcohol al interior de sus instalaciones (Guerrero, 2008). Según lo señalaban algunos jóvenes, la "libertad" en este plantel del Colegio de Bachilleres es más restringida, "como está más chico, te tienen más vigilada, ¿no?, no te dejan salir, es escuela cerrada” (Roxana estudiante 4to semestre, Comunicación personal, 04/06/15).

Son recurrentes las críticas de los jóvenes sobre la resolución que el equipo directivo decretara en 2012 respecto a que el plantel sea "de puertas cerradas", lo que muestra las tensiones que algunas decisiones tomadas en el marco de la obligatoriedad de la EMS con 
el objetivo explícito de abatir los altos porcentajes de "deserción"12 pueden producir en estos sentidos asociados al bachillerato que, al parecer, se encuentran más o menos sedimentados entre los sujetos de la institución. Argumentan que esa medida no los deja "razonar" por sí mismos y, en cierto modo, hacerse responsables:

Este Bachilleres nos sigue tratando como nińos, eso de que cierran las puertas y cosas así, es como que no dejan que los chavos empiecen a razonar y quieran entrar y cosas así, los están mimando un poco. Entonces, no me parece que cierren las puertas, ya no te formas de... es así como de "ah, pues tengo que entrar porque, qué voy a hacer", y no así de "tengo que entrar güey, aunque esté la puerta abierta y pueda hacer otras cosas", no sé, cosas así (Abraham estudiante 2do semestre, Comunicación personal, 18/05/15).

Algunos docentes también se manifestaban en contra de esta medida, por considerar que "son factores que han influido en la irresponsabilidad de los jóvenes ... entonces ahorita una manera de tener permanencia es cerrar puertas... es así como, obligado" (Profesora de Biblioteconomía, Comunicación personal, 15/03/16). Incluso plantean que desde que se "cerraron las puertas, no pueden salir, desde entonces, esto es un desbarajuste porque los muchachos se drogan acá atrás y, entonces, no, pues" (Profesora de Lenguaje, Comunicación personal, 15/03/16).

Los jóvenes del plantel se apropian, en el sentido de Rockwell (2005), de este "discurso moral" de la libertad como relativa a las consecuencias de lo que uno hace (Hernández, 2008). Pero hay matices -y algunas tensiones- entre las perspectivas de los estudiantes al respecto. Como vimos, hay quienes se quejan del control y vigi-

\footnotetext{
${ }^{12}$ Entre las medidas institucionales en pos de reducir el porcentaje de "deserción", vinculadas a la "asistencia", también sobresalen las siguientes: -Detección oportuna de las asignaturas con alto índice de ausentismo. -Atención de los reportes de inasistencia de alumnos por parte de los profesores. -Plática con los profesores que tienen alto índice de ausentismo, con la finalidad de sensibilizarlos para que implementen nuevas estrategias y formas de evaluación. -Juntas con padres de familia al inicio del semestre y posteriormente para dar a conocer el avance académico de sus hijos, en el cual se capturan las inasistencias. -Realizar rondines con el personal de confianza para detectar a los alumnos fuera de clase. -Informar a los padres de familia, ya sea con citatorio o por vía telefónica, de la ausencia de sus hijos en las clases (Plantel, Colegio de Bachilleres, 2012).
} 
lancia por considerarlos excesivos. Otros que también lo consideran negativo, pero al mismo tiempo plantean que es mejor que el plantel "no sea de puertas abiertas porque, obviamente, no van a llegar” (Roxana estudiante 4to semestre, Comunicación personal, 04/06/15). Algunos piensan, incluso, que sería "necesario" que, "si te ven aquí [en la cafetería], te lleven a tu salón, algo así”, como Sandra, que comentaba que eso la "hubiera ayudado mucho" para no reprobar tantas materias (Sandra estudiante 2do semestre, Comunicación personal, 24/06/15). Pablo planteaba que es mejor que sea un plantel de "puertas cerradas", "pues, porque te obligan a que, de cierta manera, entres a clase", y agregaba que "hay que tener mucha madurez para llevar la libertad, porque si no la agarras como libertinaje y, pues, ya" (Pablo estudiante 2do semestre, Comunicación personal, 12/03/15).

Entre los jóvenes que en algún momento interrumpieron ${ }^{13}$ su trayectoria escolar, pero retornaron a los estudios, aparece la idea de que la "responsabilidad" se aprende en la práctica, en el ejercicio de la "libertad" de decidir (Hernández, 2008), muchas veces a partir de lo que significan las propias equivocaciones. En ese sentido, Raúl contaba, en relación con su examen de ingreso al bachillerato, "la primera vez no me quedé, tampoco le eché ganas, después aprendí que sí tenía que estudiar" (Raúl estudiante 2do semestre, Comunicación personal, 12/02/15). Y Pablo relataba: "tomé malas decisiones ... tuve que empezar a trabajar para ayudar en la casa ... y aprendí que tengo que estudiar porque, neta, la vida no está fácil" (Pablo estudiante 2do semestres, Comunicación personal, 12/03/15). Guerrero (2006, 2008) denomina "punto de retorno" (turning point) a aquel giro que experimentan en su experiencia escolar algunos jóvenes de bachillerato que se alejaron de la vida académica (no necesariamente de la escuela), pero retornaron, que sentaría las bases para este significado: "el ejercicio de la libertad con responsabilidad" (Guerrero, 2006, p. 483).

\footnotetext{
${ }^{13}$ La idea de "interrupción" hace referencia a "cualquier evento que suponga un corte en la continuidad de la trayectoria escolar" (Blanco, 2014, p. 39). La "interrupción temporal" se diferencia de la "definitiva" en cuanto implica que el estudiante no asiste durante un tiempo, pero luego reingresa al sistema (Blanco, 2014). Además, en este trabajo se consideran, dentro de las "interrupciones temporales", aquellas que implican la no asistencia a clases durante un lapso de tiempo determinado, aunque no necesariamente conlleve el no ingreso a las instalaciones del plantel.
} 
Los jóvenes resaltan algunos aprendizajes que van construyendo en el transcurso de sus experiencias escolares, como comenzar a valorar los estudios o aprender a separar los "problemas personales" de las "responsabilidades académicas":

Tenía novia (se ríe), y fue así, de lo más importante, me gustaba más estar con ella que estar en mis clases y ahí fue cuando empecé a dejar de entrar, yo sí entraba más, pero después hubo el rompimiento y fue cuando, de todas maneras, no quise venir y no quería hacer nada. Y fue cuando el maestro de Ética habló conmigo, se dio cuenta de que no entraba y eso (silencio)... y iqué bueno que se dio cuenta!, porque no me había pasado nunca esto de caer tanto (silencio), pues, bueno, ya sé que no debo de hacer eso otra vez, sí tengo que separar las cosas (Abraham estudiante 2do semestre, Comunicación personal, 18/05/15).

En el proceso de apropiación del sentido moral de la "libertad con responsabilidad" entre estos jóvenes puede jugar un papel relevante la interacción con un adulto que "se dio cuenta" y supo aconsejarlos en el momento indicado. Pero la apropiación del sentido de la "libertad con responsabilidad" también se produce a partir del intercambio o contrastación de vivencias con los pares, ya sean amigos, compañeros o familiares:

Por ver experiencias de mis primos, que no entraban, dije "yo no quiero ser así, yo quiero tener, pues, así como... valor o más responsabilidad de yo entrar a mis clases por mí misma"; entonces, también, más que nada, por eso he sacado la escuela ... lo hago más por mí, no porque venga mi mamá así, diario, y que tenga que aventarme a la escuela, no; yo solita, me gusta, me gusta la libertad (Paola estudiante 2do semestre, Comunicación personal, 06/05/15).

Sabemos que el "Otro" -en este caso un adulto o un par- es central en el proceso de "formación" (Bildung) y "subjetivación" de los jóvenes. Estos conceptos "describen el proceso de desarrollo de capacidades como un proceso de (auto)formación en el contexto 
de la interacción intersubjetiva" (Weiss, 2015, p. 9). Interacción con pares o con educadores que pueden apoyar a los jóvenes en ese proceso formativo, un apoyo que a veces también puede incluir la exigencia del "cumplimento de tareas y el señalamiento de límites" (Weiss, 2015, p. 10).

\section{DISCUSIONES Y CONCLUSIONES}

Los aportes que puede realizar una investigación etnográfica como la que aquí presento se vinculan, fundamentalmente, con la visibilización y descripción de aspectos de la cotidianidad escolar que aparecen naturalizados, no siempre documentados. De allí que, en este apartado final, me propongo retomar las principales relaciones que pude identificar y describir, pues pueden servir de insumo para quienes poseen la responsabilidad y el poder de decisión en la construcción de propuestas políticas o institucionales para la educación media superior, las que pueden enriquecerse si incluyen, en su construcción, las voces de los protagonistas, las prácticas y sentidos que elaboran, en este caso, en relación con la asistencia a clases, en el contexto de la obligatoriedad de la EMS.

Las transformaciones que en los últimos años se han producido a nivel de las políticas educativas y los desafíos que las mismas plantean ponen de manifiesto la necesidad de investigar lo que está sucediendo con la Educación Media Superior en México. Estas transformaciones y la centralidad de este nivel educativo en la agenda política mexicana se inscriben en procesos a escala latinoamericana de ampliación de la cobertura en este nivel que está cambiando su sentido. Como afirma Bellei (2012, p. 220) la educación media ya no se concibe como un privilegio, ahora está cada vez más siendo considerara parte constitutiva de la educación que todo ciudadano debiera poseer.

Ya que el abordaje de esta problemática se inscribe en la preocupación, más amplia, por la acreditación de asignaturas en la cotidianidad escolar en el contexto de la obligatoriedad de la EMS (objetivo de la investigación que la contiene), el foco de la indagación estuvo centrado en documentar cómo se configura uno de los criterios de acreditación escolar en la cotidianidad de un plantel del 
Colegio de Bachilleres: la asistencia a clases. La acreditación escolar y los modos concretos en que se van construyendo los criterios que la configuran son aspectos importantes para la permanencia de los jóvenes en la escuela. Estos criterios son producto de los intercambios y negociaciones entre sujetos en la institución escolar y no todos tienen el mismo peso relativo en la acreditación de los cursos. A partir del trabajo de campo realizado advertí que la asistencia a clases es un criterio de acreditación fundamental y constituye una preocupación central en la vida cotidiana de este plantel. Dicha preocupación se inscribe en la tendencia más general de tratar de disminuir los índices de abandono escolar que se está fomentando desde las políticas educativas. Como describí, en esta escuela, coordinadas por el equipo directivo, se tomaron medidas concretas en pos de mejorar los niveles de asistencia a clases, como controlar el ingreso/egreso de los jóvenes al plantel (volverlo de "puertas cerradas") o llamar a los padres de los estudiantes que tienen inasistencias reiteradas. Si bien hay docentes que no dan tal relevancia al control de la asistencia, planteando que, por sí misma, ésta no garantiza el aprendizaje, predomina, sobre todo entre los profesores coordinadores, una mirada reprobatoria hacia la rigidez y exigencia de algunos docentes a propósito del control de la asistencia y la puntualidad en el ingreso a clases de los jóvenes.

A su vez, vimos que los motivos por los cuales los estudiantes manifiestan que no ingresan o llegan tarde a clases incluyen: la distancia del hogar al plantel; que el docente ya entregó calificaciones; otras actividades que se superponen; los estilos y exigencias de los docentes; la "flojera" (no tener ganas); preferir pasar el rato con sus amigos y novios. Este último motivo, entre otros, ha sido indagado por los estudios de la línea de investigación sobre Jóvenes y escuela del Departamento de Investigaciones Educativas del Cinvestav, que ponen de relieve que la escuela también es vivida y significada por los estudiantes como "espacio de vida juvenil" (Weiss, 2012, 2015). A veces las posibilidades de la vida juvenil compiten con las exigencias escolares, pero no siempre es así (Weiss, 2012, 2015). Como he documentado, en ocasiones las amistades influyen en la decisión de faltar, pero también pueden incidir en forma contraria, convenciendo a los amigos de asistir a clase. $\mathrm{Al}$ respecto vale destacar 
el dinamismo presente en la decisión de ingresar o no a clases por parte de los estudiantes, a partir de la confluencia de aspectos que, en ocasiones, pueden favorecer la asistencia y, en otras, desalentarla. Dando lugar a una lectura retrospectiva que, a veces, es significada en términos de arrepentimiento.

En el estudio de las estrategias estudiantiles prima la interpretación de Dubet y Martuccelli (1998, p. 315) acerca de los liceístas franceses como verdaderos "estrategas", "comprometidos en un vínculo de utilidad con sus estudios" ("instrumentalismo escolar"). También se suele analizar en términos de una "disposición general" de los jóvenes para hacer frente a las expectativas institucionales y lograr la aprobación con la inversión de un mínimo esfuerzo, como las estrategias de estudiantes de clase media (como "zafar") analizadas por Meo (2011) en Argentina. Desde la línea de estudios sobre Jóvenes y escuela del DIE-Cinvestav se han documentado algunas estrategias de los estudiantes mexicanos para cumplir con las exigencias escolares sin sacrificar necesariamente su vida juvenil, pero destacando que la lógica estratégica utilitarista que generalmente guía estas prácticas, también puede estar orientada por un marco moral (Hernández, 2008, Weiss, 2012).

En las entrevistas con los jóvenes, la decisión de entrar o no a clases y la entrega de trabajos y tareas escolares (cuestión en la que no profundicé aquí por razones de espacio) aparecían atravesadas por el sentido moral, asociado al bachillerato, del "ejercicio de la libertad con responsabilidad". La "libertad" es significada como la posibilidad de decidir por sí mismos y es valorada positivamente por los estudiantes. Pero los jóvenes se apropian de este discurso moral de la "libertad" como relativa a las consecuencias de lo que uno hace (Hernández, 2008), no sin tensiones. Hay estudiantes que se quejan de las prácticas institucionales de control y vigilancia por considerarlas excesivas y otros afirman que sería necesario, para no reprobar tantas materias, que los obligaran a entrar a clases, por ejemplo. Estas tensiones podrían estar expresando el deseo de los jóvenes de contar con un mayor margen de libertad y autonomía en la toma de decisiones, pero también la necesidad de un acompańamiento y la relevancia del "Otro" en ese proceso de "formación" (Bildung) y "subjetivación”. 
Este sentido del bachillerato como un espacio donde los jóvenes deben apropiarse del sentido moral de la "libertad con responsabilidad" también se encuentra presente en el discurso de algunos docentes y coordinadores del plantel. Allí aparece ligado a la idea de la "autorregulación del aprendizaje" que, a su vez, se enlaza con el enfoque del aprendizaje por competencias recuperado fuertemente a partir de la Reforma Integral de la Educación Media Superior (reforma curricular de 2008). Esa exigencia hacia los sujetos de "hacer un uso permanente de la reflexividad" para orientarse en la vida social se constituye, según la tesis de la individualización (Beck, Giddens, Bauman, Lash, citados en Martuccelli, 2006), como una característica central de las sociedades contemporáneas donde las instituciones tienden a responsabilizarnos cada vez más de lo que nos acaece y la tradición y hábitos heredados ya no sirven más de guía para la acción (Martuccelli, 2006). En esta investigación, sin embargo, la tesis de la individualización podría entrar en tensión con ciertas transformaciones que se van produciendo a nivel de la cotidianidad escolar y que estarían dando cuenta de que hay una mayor intervención de las instituciones escolares en la vida de los jóvenes -como hacer el plantel de "puertas cerradas" y los nuevos procedimientos implementados para prevenir el abandono -como la reunión con padres de estudiantes que reprobaron o el llamado a los mismos ante las inasistencias reiteradas de sus hijos- y que apuntan a cumplir con la obligatoriedad de la EMS. Este argumento, no obstante, debería ser revisado, profundizado o complementado con otros estudios de mayor alcance.

Algunas prácticas cotidianas escolares vinculadas a la acreditación de asignaturas regulares como la flexibilidad y permisividad en relación con la puntualidad o el poder aprobar con "pura asistencia" en algunas materias; así como otras prácticas que documenté en la investigación, pero no fueron desarrolladas aquí por cuestiones de extensión (como la escasa exigencia de tareas para realizar fuera del horario escolar; la tendencia a evaluar casi exclusivamente a partir de los trabajos realizados en clase -las llamadas "evidencias"-, reduciendo la toma de exámenes y otras formas de evaluación; la proliferación de mecanismos de recuperación de asignaturas reprobadas; entre otros), se vinculan con el mandato por mejorar los índices de 
reprobación y abandono presente en las políticas educativas actuales. La flexibilización y revisión de los reglamentos escolares en pos de mejorar las tasas de aprobación de hecho fue una de las líneas de trabajo presentada en la XLII Reunión del Consejo Nacional de Autoridades Educativas (CONAEDU) de 2013 (Weiss, 2015, p. 144).

Pero este mandato se traduce y es resignificado de diferentes maneras en la cotidianidad escolar. Las posiciones de los docentes entrevistados en relación con el mismo son variadas. Algunos profesores denuncian abiertamente que ciertos mecanismos institucionales favorecen la práctica de "hacer pasar" o aprobar a los estudiantes sin que se hayan apropiado de los conocimientos considerados necesarios. Esto se puede identificar en la normativa que regula el sistema de estímulos económicos al desempeño docente en el Colegio de Bachilleres, donde el "Modelo de evaluación" que determina la asignación de dichos estímulos incluye, entre sus criterios más importantes, el "porcentaje de permanencia de los alumnos atendidos por el docente" (medido a partir de las asistencias/inasistencias/ interrupción); el "porcentaje de aprobación de los alumnos atendidos por el docente" y el "porcentaje de alumnos atendidos por el profesor con calificación final entre 8 y 10" (Plantel Colegio de Bachilleres, 2015). Los jóvenes entrevistados afirman que algunos docentes "te regalan tus puntos" (Paola estudiantes 2do semestre, Comunicación personal, 06/05/15) y, como mencioné, la rigidez de quienes no dan oportunidades extras a los estudiantes es objeto de crítica por parte de coordinadores del plantel.

Quizás estas posibilidades más flexibles de acreditación contribuyan a mejorar los índices de permanencia y aprobación en la EMS, pero no debemos perder de vista los "efectos no deseados" (Popkewitz, 1994) que estas orientaciones pueden llegar a producir. Aunque este mandato no se impone en forma lineal, uno de los peligros señalados en las investigaciones sobre la temática es que se produzca algo similar a lo que sucede en el nivel secundario mexicano donde, recurrentemente, se otorgan calificaciones aprobatorias sin que se cumplan los objetivos formativos, ofreciendo una educación de baja calidad para la mayoría (Weiss, 2012). De este modo, en la EMS -que desde 2012 es también obligatoria- se puede favorecer la proliferación de prácticas de acreditación escolar que permitan apro- 
bar a los estudiantes, aunque no se hayan apropiado necesariamente de los conocimientos esperables. En palabras de Latapí (1980, p. 98) "se hermosearán, ciertamente, las estadísticas escolares, pero tener más alumnos aprobados no significará un mejor sistema educativo".

\section{REFERENCIAS BIBLIOGRÁFICAS}

Achilli, E. (2005). Investigar en Antropología Social. Los desafios de transmitir un oficio. Rosario: Laborde Editor.

Achilli, E. (2010). Escuela, familia y desigualdad social. Una antropología en tiempos neoliberales. Rosario: Laborde Editor.

Amador, J. C. (2008). La evaluación y el diseño de politicas educativas en México. México: CESOP. Recuperado de www3.diputados.gob.mx/ camara/content/.../Educacion_docto_35.pdf

Ávalos, J. (2009). La vida juvenil en el Bachillerato. Una mirada etnográfica. X Congreso Nacional de Investigación Educativa. Consejo Mexicano de Investigación Educativa. Veracruz, México. Recuperado de http:// www.comie.org.mx/congreso/memoriaelectronica/v10/pdf/area_tematica_16/ponencias/0996-F.pdf

Bellei, C. (2012). Políticas educativas para el nivel secundario: complejidades y convergencias. En E. Tenti (ed.), La escolarización de los adolescentes: desafíos culturales, pedagógicos y de politica educativa (pp. 209253). Buenos Aires: IIEP-UNESCO.

Blanco, E. (2014). Interrupción de la asistencia escolar: desigualdad social, instituciones y curso de vida. En E. Blanco, P. Solís y H. Robles (eds.), Caminos desiguales. Trayectorias educativas y laborales de los jóvenes en la Ciudad de México (pp. 39-70). México: El Colegio de México-INEE.

Blanco, E., Solís, P., y Robles, H. (2014). Caminos desiguales. Trayectorias educativas y laborales de los jóvenes en la Ciudad de México. México: El Colegio de México-INEE.

Bourdieu, P., y Passeron, J. C. (1998). La reproducción. Elementos para una teoría del sistema de enseñanza. México: Fontamara.

Campos, R., y Urbina, F. (2011). Desempeño educativo en México: la prueba Enlace. Estudios Económicos, 26(2), 249-292. Recuperado de http://www.redalyc.org/articulo.oa?id=59720807004

Colegio de Bachilleres. (2010). Reglamento general de los alumnos. Recuperado de http://www.cbachilleres.edu.mx/cb/enlaces_internos/Reglamentogeneralcb.pdf 
Comipems (2016). Listado de opciones educativas. Página oficial de Comipems. Recuperado de http:// opciones.comipems.org.mx

Conaedu. (2015). XLII Reunión del Consejo Nacional de Autoridades Educativas-Capitulo EMS. México: SEMS. Recuperado de http://www. sems.gob.mx/work/models/sems/Resource/12125/52_CONAEDU_ EMS.pdf

De Ibarrola, M. (2012). Los grandes problemas del sistema educativo mexicano. Perfiles Educativos, XXXIV, 16-28. Recuperado de http:// www.redalyc.org/articulo.oa?id=13229959003

Diario Oficial de la Federación. (2012). Decreto por el que se declara reformado el párrafo primero; el inciso c) de la fracción II y la fracción $V$ del artículo 3o., y la fracción I del artículo 31 de la Constitución Política de los Estados Unidos Mexicanos. México: Gobierno de la República. Recuperado de http://www.dof.gob.mx/nota_detalle.php?codigo=52330 $70 \&$ fecha $=09 / 02 / 2012 \&$ print $=$ true

Dore, R. (1980). The Diploma Disease Revisited. Institute of Development Studies Bulletin, 11(2). Recuperado de https://www.ids.ac.uk/files/ dmfile/Dore11.2final.pdf

Dubet, F., y Martuccelli, D. (1998). En la escuela. Sociología de la experiencia escolar. Buenos Aires: Losada.

Estrada, M. J. (2014). Afiliación juvenil y desafiliación institucional. El entramado complejo de la deserción en la educación media. Revista Mexicana de Investigación Educativa, 19(61), 431-453. Recuperado de http://www.scielo.org.mx/pdf/rmie/v19n61/v19n61a5.pdf

Estrada, M. J. (2015). Educación superior y deserción juvenil. Una mirada desde las historias de vida. Hermosillo, México: El Colegio de Sonora.

Ezpeleta, J. (2004). Innovaciones educativas. Reflexiones sobre los contextos en su implementación. Revista Mexicana de Investigación Educativa, 9(21), 404-423. Recuperado de http://www.oei.es/reformaseducativas/reflexiones_innovaciones_educativas_ezpeleta.pdf

Granja, J. (1988). Los procesos formales de legitimación de los aprendizajes escolares: rituales normativos, saberes legitimos, sujetos constituidos. El caso de la enseñanza tecnológica agropecuaria del nivel medio superior. (Tesis de maestría). Departamento de Investigaciones Educativas, Cinvestav, México.

Grijalva, O. (2011). La diversión y el trabajo académico como fuentes de las identificaciones de los jóvenes en sus grupos de pares. Revista de 
Investigación Educativa, 12, 1-21. Recuperado de https://www.uv.mx/ cpue/num12/inves/grijalva-diversion-trabajo.html

Guerra, M. I. (2008). Trayectorias escolares y laborales de jóvenes de sectores populares. Un abordaje biográfico. (Tesis de doctorado). Departamento de Investigaciones Educativas, Cinvestav, México.

Guerrero, M. E. (2008). Los estudios de bachillerato: un acercamiento a la perspectiva juvenil. (Tesis de doctorado). Departamento de Investigaciones Educativas, Cinvestav, México.

Guerrero, M. E. (2006). El punto de retorno. Una experiencia de bachillerato universitario. Revista Mexicana de Investigación Educativa, 11(29), 483-507. Recuperado de http://www.redalyc.org/articulo. oa?id $=14002908$

Hernández, J. (2008). El trabajo sobre la identidad en estudiantes de bachillerato: reflexividad, voces y marcos morales. México: Universidad Pedagógica Nacional.

INEE. (2011). La educación media superior en México. Informe 2010-2011. México: INEE. Recuperado de http://www.inee.edu.mx/index.php/ acerca-del-inee/68-publicaciones/informes-anuales-capitulos/406-laeducacion-media-superior-en-mexico

Jackson, P. W. (1998). La vida en las aulas. Madrid: Morata.

Kantor, D. (2015). Escuela media y condición juvenil. Distancias, aproximaciones, sentidos. Clase 9: Escuela secundaria y condición juvenil ¿Cómo es posible estar en la escuela? Estrategias que promueven o desalientan esa permanencia. Curso de posgrado "La educación secundaria: temas y problemas en perspectiva latinoamericana." Buenos Aires: FLACSO.

Kisilevsky, M. (2009). La evaluación de políticas y programas: desafíos para la gestión en educación. En E. Martín y F. Martínez Rizo (eds.), Avances y desafios en la evaluación educativa (pp. 81-88). Madrid: OEIFundación Santillana. Recuperado de http://www.oei.es/noticias/spip. php?article9225

Latapí, P. (1999). La moral regresa a la escuela: reflexiones sobre la ética en la educación mexicana. México: UNAM.

Latapí, P. (1980). Análisis de un sexenio de educación en México, 1970-1976. México: Nueva Imagen.

Martínez Rizo, F. (2009). Evaluación formativa en aula y evaluación a gran escala: hacia un sistema más equilibrado. Revista Electrónica de Inves- 
tigación Educativa, 11(2), 1-18. Recuperado de http://redie.uabc.mx/ redie/article/view/231

Martinic, S. (2010). La evaluación y las reformas educativas en América Latina. Revista Iberoamericana de Evaluación Educativa, 3(3), 31-43. Recuperado de http://www.rinace.net/riee/numeros/vol3-num3/art2. html

Martuccelli, D. (2006). Lecciones de Sociología del individuo. Lima: Departamento de Ciencias Sociales.

Meo, A. (2011). Zafar, so good. Middle-class students, school habitus and secondary schooling in the city of Buenos Aires (Argentina). British Journal of Sociology of Education, 32(3), 349-367. Recuperado de http://dx.doi.org/10.1080/01425692.2011.559338

Miranda, F. (2012). Los jóvenes contra la escuela. Un desafío para pensar las voces y tiempos para América Latina. Revista Latinoamericana de Educación Comparada, 71, 71-84. Recuperado de http://www.saece. org.ar/relec/revistas/3/art6.pdf

Muñoz, C., Rodríguez, P. G., Restrepo, P., y Borrani, C. (1979). El síndrome del atraso escolar y el abandono del sistema educativo. Revista Latinoamericana de Estudios Educativos, IX(3), 1-60. Recuperado de https://www.redalyc.org/articulo.oa?id=27035407

Plantel-Colegio de Bachilleres (2015). Total de grupos/alumnos, semestre 2015A. México: Plantel Colegio de Bachilleres

Plantel-Colegio de Bachilleres (2014a). Iniciativa para la mejora educativa: "Fortalecimiento Académico para disminuir el abandono escolar en el año 2015". México: Plantel, Colegio de Bachilleres.

Plantel-Colegio de Bachilleres (2012). Plan de Mejora Continua 2012-2013. Recuperado de www.sistemadeevaluacion.sems. gob.mx/eym2/tdocs/653_6985_2012plan_academico.12_02. $\mathrm{docx}+\& \mathrm{~cd}=2 \& \mathrm{hl}=\mathrm{es} \& \mathrm{ct}=\mathrm{clnk} \& \mathrm{gl}=\mathrm{mx}$

Poggi, M. (2008). Hacia la construcción de uevas estrategias de evaluación de la calidad educativa en América Latina. En Reflexiones en torno a la evaluación de la calidad educativa en América Latina y el Caribe (pp. 35-48). Santiago, Chile: UNESCO-LLECE. Recuperado de http:// unesdoc.unesco.org/images/0017/001776/177648S.pdf

Popkewitz, T. (1994). Sociología politica de las reformas educativas. El poderl saber en la enseñanza, la formación del profesorado y la investigación. Madrid: Morata. 
Ramírez, R. (2012). Cambiar, interrumpir o abandonar: la construcción de experiencias de los estudiantes en su tránsito por una institución de educación superior tecnológica. México: ANUIES.

Ramírez, R., y Torres, M. C. (2015). Desafíos centrales y avances de la política educativa hacia la Educación Media Superior. En R. Ramírez (ed.). Desafios de la Educación Media Superior (pp. 219-236). México: Instituto Belisario Domínguez-Senado de la República.

Rockwell, E. (1995). La Escuela Cotidiana. México: Fondo de Cultura Económica.

Rockwell, E. (2005). La apropiación, un proceso entre muchos que ocurren en ámbitos escolares. En Memoria, conocimiento y utopía. Anuario de la Sociedad Mexicana de Historia de la Educación (pp. 28-38). Barcelona: Pomares.

Rockwell, E. (2009). La experiencia etnográfica: historia y cultura en los procesos educativos. Buenos Aires: Paidós.

Rockwell, E. (2013). La complejidad del trabajo docente y los retos de su evaluación: resultados internacionales y procesos nacionales de reforma educativa. En R. Ramírez (ed.), La reforma constitucional en materia educativa: alcances y desafíos (pp. 77-109). México: Instituto Belisario Domínguez.

Rockwell, E., y Ezpeleta, J. (1985). La escuela: relato de un proceso de construcción inconcluso. En Educação na América Latina, Os modelos teóricos e realidade social (pp. 151-172). São Paulo: Cortez Editora Editora Autores Asociados.

Saccone, M., y Weiss, E. (2017). La acreditación de asignaturas en la vida cotidiana escolar. Un estudio etnográfico en el contexto de la obligatoriedad de la educación media superior. Propuesta Educativa, 26(47), 119-128.

Saucedo, C. (1998). Expresiones genéricas de los adolescentes en el contexto sociocultural de un CONALEP. (Tesis de maestría). Departamento de Investigaciones Educativas, Cinvestav, México

Schmelkes, S. (2013). La evaluación del desempeño profesional docente. En R. Ramírez (ed.), La reforma constitucional en materia educativa: alcances y desafíos (pp. 111-122). México: Senado de La República, Instituto Belisario Domínguez. Recuperado de http://odisea.org.mx/ centro_informacion/educacion/libro/Reforma_Const_Ed.pdf 
SEMS. (2012). Reporte de la Encuesta Nacional de Deserción en la Educación Media Superior. México: SEMS. Recuperado de http://www.sems.gob. mx/work/models/sems/Resource/10787/1/images/Anexo_6Reporte_ de_la_ENDEMS.pdf

Simmel, G. (2002). Sobre la individualidad y las formas sociales: escritos escogidos. Buenos Aires: Universidad Nacional de Quilmes

Solís, P., Leal, A., y Brunet, N. (2014). Abandono escolar del primer semestre de la generación 2013-B del Colegio de Bachilleres. Informe final. México: Área de Investigación y Prospectiva-Dirección General del Colegio de Bachilleres.

Treviño, E. (2006). Evaluación del aprendizaje de los estudiantes indígenas en América Latina. Desafíos de medición e interpretación en contextos de diversidad cultural y desigualdad social. Revista Mexicana de Investigación Educativa, 11(28), 225-268. Recuperado de http://www. redalyc.org/articulo.oa?id=14002812

Villa, L. (2007). La educación media superior ¿igualdad de oportunidades? Revista de La Educación Superior, XXXVI(141), 93-110. Recuperado de http://www.redalyc.org/articulo.oa?id=60414105

Weiss, E. (2012). Jóvenes y bachillerato. México: ANUIES.

Weiss, E. (2014). El abandono escolar en la educación media superior. Informe de investigación para la Dirección General de Investigación Estratégica del Instituto Belisario Domínguez. México: Instituto Belisario Domínguez.

Weiss, E. (2015a). El abandono escolar en la Educación Media Superior: dimensiones, causas y políticas para abatirlo. En R. Ramírez (Ed.), Desafios de la Educación Media Superior (pp. 81-159). México: Instituto Belisario Domínguez-Senado de la República.

Weiss, E. (2015). Más allá de la socialización y de la sociabilidad: jóvenes y bachillerato en México. Revista Educação e Pesquisa, 41, 1257-1272. Recuperado de http://dx.doi.org/10.1590/S1517-9702201508144889

Weiss, E. (2016). La apropiación de una innovación. La hora de Orientación y tutoría en escuelas secundarias. Revista Electrónica de Investigación Educativa, 18(2), 1-26. Recuperado de http://redie.uabc.mx/ redie/article/view/1136/1350

Weiss, E. (2018). Los significados del bachillerato para los jóvenes y la permanencia escolar en México. Sinéctica. Revista Electrónica de Educación, (51), 1-19. Recuperado de www.sinectica.iteso.mx 